\title{
Speed Control of Peanut Planting System
}

\author{
Aye Aye Tun*, Zaw Ngwe \\ ${ }^{* 1}$ Department of Mechatronic, Technological University, Kyaukse, Myanmar \\ 2Department of Electronic, Technological University, Maubin, Myanmar
}

\begin{abstract}
This paper is aimed to control the speed of peanut planting system. The system introduces a control mechanism to drop the seeds at a particular position with specified distance, to achieve desired seed rate within the row, uniform seed spacing and alarm system. The overall system includes motion sensor, proximity induction sensor, two servo motors, three DC motors and alarm system. These parts are controlled by Arduino Mega 2560 which is the heart of the system. The battery 12V, 5AH Lead Acid Battery is used for the whole system. So, the wheel motors of machine are controlled by PWM DC motor speed controller separately. Another DC motor is used to stir the seeds within the seed storage tank. When there is no seed to detect within the seed storage tank, it sends the signal to the Arduino and indicates the alarm. To get equal seed spacing or seed to seed distance, proximity induction sensor is used. Servo motors are used for precise control of seed rating. The paper presents calculation of gear ratio, desired motor RPM, PWM out level are also described completely.
\end{abstract}

Keywords : Control Mechanism, Arduino Mega 2560, Sensors, DC Motors, RPM, PWM

\section{INTRODUCTION}

Agriculture is the largest livelihood provided in Myanmar mostly in the rural area. For developing the economical condition of Myanmar, it must be necessary to increase our agricultural productivity and quality. The conventional method for agribusiness is manual one but it requires more time and more efforts. So it's a time to automate the sector to overcome this problem. Instrumentation and control system plays an important role today. The innovative idea of this proposed system is to sow three seeds per drop accurately with equal spacing and the machine to be moved along the straight line.

In this proposed system, the researcher aims to sow the standard size of three peanut seeds per drop for the farming process with great efficiency. By using the planting machine, the farmers can avoid wastage of seed, get high productivity of agricultural products, and reduce time and human efforts. There are more advantages for using seed sowing system than any other parameters.

The other objectives of this research paper are to

- To design and calculate gear ratios, motor RPM and PWM for the seed sowing system.

- To achieve equal spacing and straight line movement

- To get three seeds per drop

In order to get straight line movement, the speed of wheel motor is controlled by PWM motor speed controller. The desired distance or equal spacing is done by proximity induction sensor sending signal to the Arduino. To obtain three seeds per drop, servo motors are used by controlling the seed rate. In this 
research, mechanical design is also important to develop the system harmonically. The basics of power electronics, designing, calculation, simulation and practical implementation of the proposed system are also fundamental for this development. The peanut planting system could help the small scale farmers for doing the farming process with great efficiency and accuracy

\section{SYSTEM OVERVIEW}

The overall block diagram of the seed sowing system is composed of microcontroller Mega2560, motion sensors, proximity induction sensor, DC motors and servo motors. The desired seed spacing or distance can be measured with the proximity induction sensor by detecting the iron plate which is designed and placed on the shaft of wheel. The motion sensor will sense whether the seeds are presented on the storage tank or not. If there is no seed to detect, the buzzer will be activated and the overall system will reset.

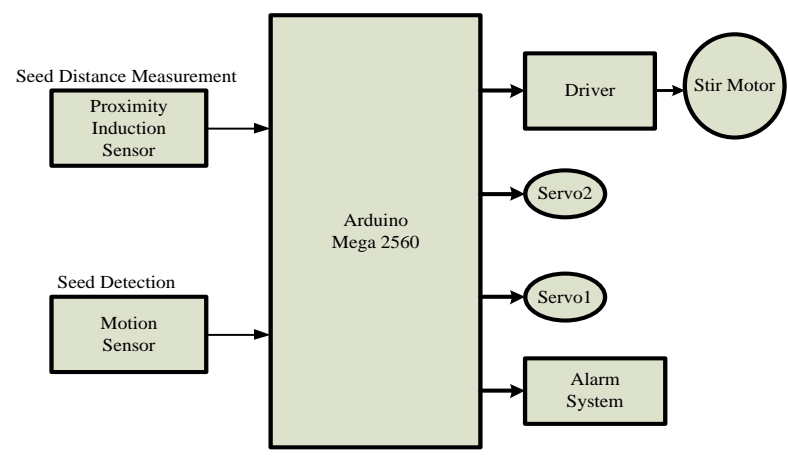

Figure1: Block Diagram of Bean Planter System

\section{FLOW CHART}

The overall flowchart of the system is shown in figure2. When the power is on, the wheel motors start to run according to the calculated RPM and then the vehicle moves along the straight line. When the motion sensor detects the seed, it gives the output signal to the Arduino. And then the stirred motor operates to get the rotation of seed within the seed storage box. In order to drop the desired seeds, the sequencing or flowing of seeds is done by first servo motor. And then, the second servo motor drops the seeds into the ground.

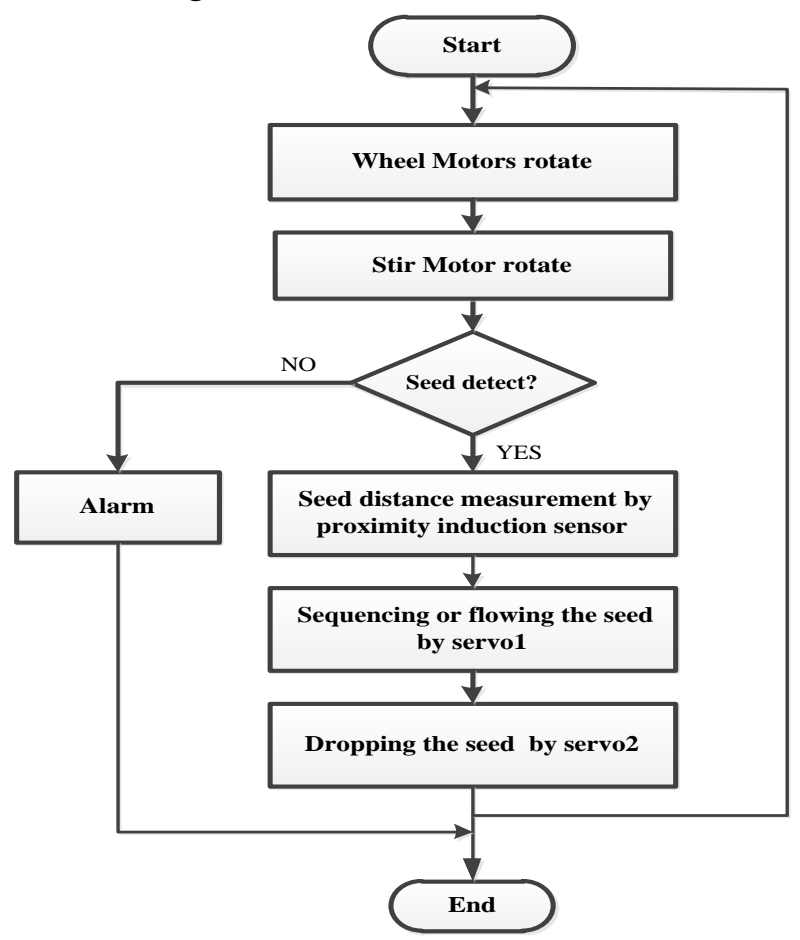

Figure 2: Flow Chart of Bean Planter System

\section{CALCULATION OF GEAR RATIO}

There are four types of gear such as spur gear, bevel gear, worm gear, helical gear. The researcher uses spur gear in this proposed system because of mostly used in series for large gear reduction. Gears of the same pitch, but differing numbers of teeth can be paired to obtain a wide range of Gear Ratios. Gear Ratios are used to increase mechanical advantage (torque) or increase rotational speed or velocity. There are three ways for power transmitting in gear applications. Among them, the main aim of gear usage in this system is for changing RPM. The ratio of a given pair of gears is calculated by dividing number of teeth on the driven by the number of teeth on drive gear.

$\mathrm{G} . \mathrm{R}=$ Driven gear teeth $:$ Drive gear teeth equation(1) 
Gear ratio for CGD1,

The number of teeth in driven gear is 67 and driver is 12 . So, the gear ratio can be calculated as:

G.R1 = Driven Gear Teeth $:$ Drive Gear Teeth

$=67: 12$

$=5.6: 1$

\section{Gear ratio for CGD2,}

The number of teeth in driven gear is 53 and driver is 8 . So, the gear ratio can be calculated as:

$$
\begin{aligned}
\text { G.R2 } & =53: 8 \\
& =6.63: 1
\end{aligned}
$$

\section{Gear ratio for CGD3,}

The number of teeth in driven gear is 43 and driver is 8 . So, the gear ratio can be calculated as:

$$
\begin{aligned}
\text { G.R3 } & =43: 8 \\
& =5.375: 1
\end{aligned}
$$

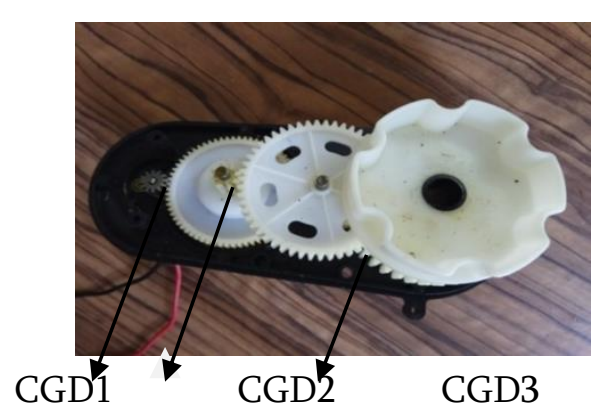

Figure3: Compound Gear Drive

The bean planting system want to sow the desired distance between seeds is 6 inches. So, the RPM of the vehicle wheel can be calculated by using the velocity equation. The final gear ratio of wheel motor above calculation is $5.375: 1$.

Velocity $($ distance/sec $)=$ Pitch Circle Circumference $\mathbf{x}$ RPM

$$
\begin{aligned}
6 \text { inches x } 60 & =\pi \mathrm{D} \text { RPM } \\
360 \text { inches } & =50.27 \text { inches } \times \mathrm{RPM} \\
\mathrm{RPM} & =7.163 \mathrm{rev} / \mathrm{min}
\end{aligned}
$$

Thus, the wheel rotates 7.163 revolutions per minute to reach the desired distance (6 inches).

\section{A. Calculation of Motor RPM}

As noted previously the ratio of compound gear drive G.R3 is 5.375:1. Thus every time the driven gear turns 5.375 revolutions, the drive gear turns 1 revolution. The RPM3 can get by multiplying RPM (7.163) and 5.375. The number of teeth of each gear is inversely proportional to the number of revolutions of each gear.

For CGD3,

$$
\begin{aligned}
\text { RPM3 } & =7.163 \times \text { G.R3 } \\
& =38.5 \mathrm{rev} / \mathrm{min}
\end{aligned}
$$

Similarly for CGD2,

$$
\begin{aligned}
\mathrm{RPM} 2 & =38.5 \times \mathrm{G} . \mathrm{R} 2 \\
& =255 \mathrm{rev} / \mathrm{min}
\end{aligned}
$$

For CGD1,

$$
\mathrm{RPM} 1=255 \times \mathrm{G} . \mathrm{R} 1=1428 \mathrm{rev} / \mathrm{min}
$$

The wheel motor must be rotated $1428 \mathrm{RPM}$ in order to get the desired distance (6 inches) as the previous calculation.

\section{B. Controlling the Speed of Wheel Motor by PWM}

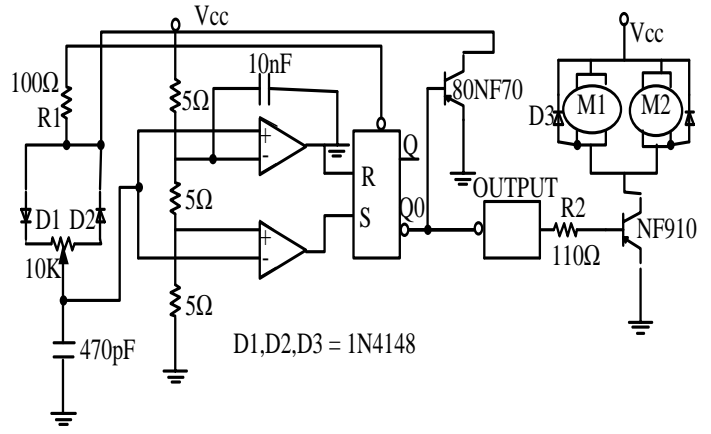

Figure 4: Control Circuit for Wheel Motors

The speed of wheel motors is controlled by regulating the amount of voltage across its terminals using PWM signal. The timing capacitor to go one complete charged and discharged cycle depends upon the value of current flowing through the timing networks of resistors. To produce the required PWM signal, 555 timer chip is used at a fixed frequency. It is 
used $10 \mathrm{k}$ potentiometer to adjust the necessary effective voltage by the relationship between the voltage and angular velocity or revolution per minute (RPM).

The relationship between the effective voltage and the angular velocity of wheel motor is followed. The time taken for capacitor $\mathrm{C}$ to go through one complete charge and discharge depends on the values of $\mathrm{RA}(\mathrm{VR}), \mathrm{RB}(\mathrm{R} 1)$ and $\mathrm{C}$.

The value of special purpose variable resistor using in this system is $10 \mathrm{k} \Omega$ to control the effective voltage.

$$
\begin{aligned}
\text { Veff } & =\mathrm{IR}+\mathrm{Ke} . \omega \\
& =\mathrm{T} / \mathrm{KT} . \mathrm{R}+\mathrm{Ke} . \omega \\
& =14.4 / 8.8235 \times 3.45+0.008823 \times 150 \\
& =6.95 \mathrm{~V}
\end{aligned}
$$$$
\text { equation (3) }
$$

The average effective voltage of $6.95 \mathrm{~V}$ must be given to the controller circuit. By using voltage divider formula,

$$
\begin{aligned}
& \mathrm{RA}(\mathrm{VR})=10 \mathrm{k} \Omega, \\
& \mathrm{RB}=100 \Omega, \\
& \mathrm{C} 1=470 \mathrm{pF}, \\
& \mathrm{V}=(\mathrm{RA}+100) /(10 \mathrm{~K}+100) \times 12 \\
& \mathrm{RA}=(6.95 / 2) \times(10 \mathrm{k}+100)-100 \\
& \mathrm{RA}=5.752 \mathrm{~K} \Omega
\end{aligned}
$$

The value of control voltage is $6.95 \mathrm{~V}$ and the variable resistor (RA) must be adjusted into $5.752 \mathrm{k} \Omega$ in order to the desired angular velocity and the desired distance.

Check ;

$\mathrm{TH}=0.693(\mathrm{RA}+\mathrm{RB}) \mathrm{C}$

(4)

$$
=3.29 \mu \mathrm{s}
$$

$$
\mathrm{TL}=0.693 \mathrm{RBC}
$$

(5)

$$
=0.0325 \mu \mathrm{s}
$$

$\mathrm{DC}=(\mathrm{TH}+\mathrm{TL}) / \mathrm{TL} \times 100 \%$

$$
\begin{aligned}
& (6)=(3.29 / 3.3225) \times 100 \% \\
& =99 \%
\end{aligned}
$$

\section{Calculating the PWM Value}

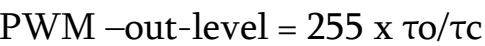

$$
\begin{aligned}
& =255 \times 0.5792 \\
& =147.69
\end{aligned}
$$

Pulse width modulation is a great method of controlling the amount of power delivered to a load without dissipating any wasted power. PWM output level of 147.69 is used in this seed sowing system according to the designed calculation.

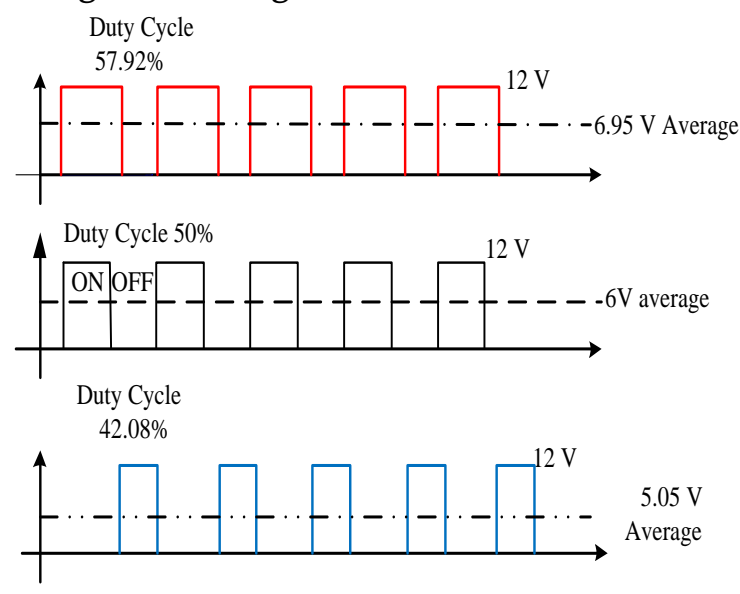

Figure 6: Output PWM Waveform

\section{EXPERIMENTAL TEST AND RESULT}

The seed planting system is focused on controlling the seed rate of peanut at the specified distance. The desired seed rate of the system is three seed per drop described in Table1 of evaluation results. By the following experimental results, the main problem faced by testing is seed lapping because size and shape of the seeds are not the same. The system is also possible to cultivate different kinds of seeds with different seed per drop.

TABLE 1. Evaluation Results for Three Peanut Seeds

\begin{tabular}{|l|l|l|l|}
\hline Item & $\begin{array}{l}\text { Testing } \\
\text { Time }\end{array}$ & $\begin{array}{l}\text { Desired } \\
\text { peanut } \\
\text { seed/drop }\end{array}$ & $\begin{array}{l}\text { Actual } \\
\text { peanut } \\
\text { seed/drop }\end{array}$ \\
\hline Peanut & 5 & 3 & 4 \\
\hline
\end{tabular}




\begin{tabular}{|l|l|l|l|}
\hline Peanut & 5 & 3 & 2 \\
\hline Peanut & 35 & 3 & 3 \\
\hline Peanut & 5 & 3 & 1 \\
\hline Total & 50 & \multicolumn{2}{|l}{} \\
\cline { 1 - 2 } & &
\end{tabular}

The desired seeds per drop are three for every testing time. The actual seeds per drop are one, two and four seeds when it was tested in five times. Consequently, the desired seeds per drop are three seeds when the testing times are 35. There are a few errors between the desired and actual seeds per drop because the size and shape of groundnut are not same in order to control the dropping seed rate.

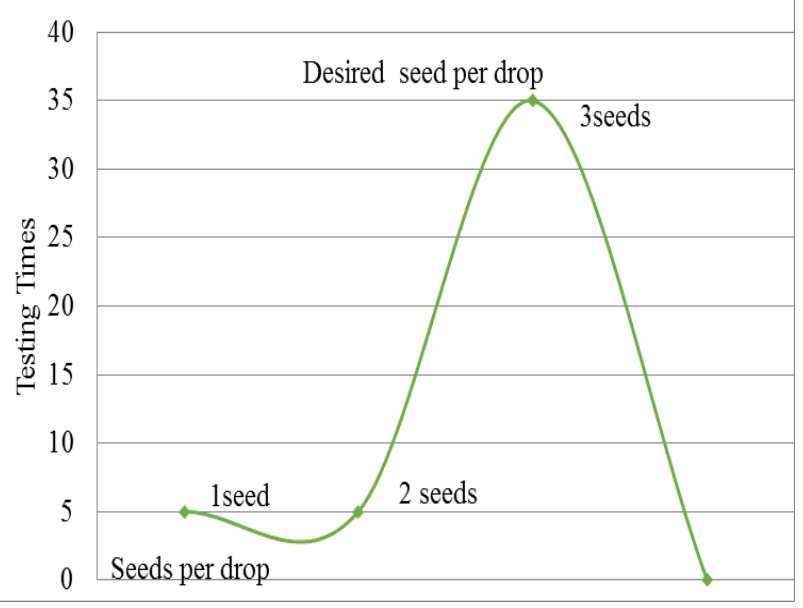

Figure7. Result Curve of peanut for Actual

The result curve of peanut between the desired seed per drop and actual seed per drop is illustrated in figure 7 . The type of the curve is of bell shape and its peak point is referred to the desired seeds per drop designed in this peanut planting system.

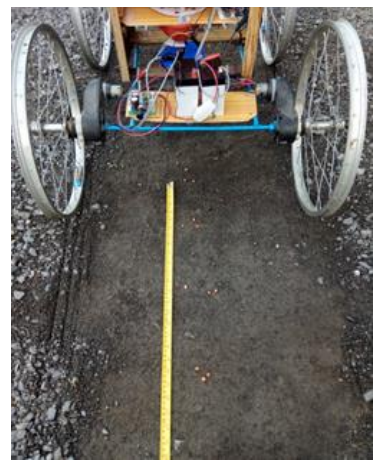

Figure 8: Experimental Test for Three Peanut Seeds per Drop
The experiment result can be clearly seen that the peanut planting machine drops three seeds with a distance of six inches. In order to do that, the motion sensor detects seed and then starts the working condition of proximity induction sensor. When the wheel is rotated, the proximity sensor detects its encoder fitted on the shaft of the wheel. The encoder is designed with eight metal plates in which each plates are arranged to get equal seed distance. As soon as the sensor detects its encoder, the first servo motor separates three seeds from the tank. The second servo drops the seed for accomplishing equal seed rate. By the following experimental result, the machine moves along the straight line but there is a little deviation due to the condition of ground. To complete the system, the quality of battery, the soil condition, the seed size and seed types are the facts that can be taken into account

\section{CONCLUSION}

In this system, the desired distance dropping the seeds on the ground is calculated with relevant gear ratio, motor RPM and necessary PWM. The lesser the RPM of wheel motor, the shorter the distance of movement. PWM controller is used to reach the required distance by adjusting the potentiometer or PWM value. Seed size is the important fact to get the best accuracy of seed sowing system and it must be the same. Moreover, soil condition, quality of battery used in this system and selection of motor are other facts that must be considered.

\section{REFERENCES}

[1] Abdulrahman.: "Seed Sowing Robot", International Journal of Computer Science Trends and Technology (IJCST) - Volume 5 Issue 2, Mar - April 2017. 
[2] P. Baladarshini.: "DESIGN AND FABRICATION OF UNIVERSAL SEED SOWING MACHINE", International Journal of Advanced Technology in Science and Technology, Vol.No.5, May 2017.

[3] Dr. Sunil K. Somani, Principal Jawaharlal Institute of Technology, Borawan, MP.: "Machine Design (In SI Units)", McGrawHill, 1980.

[4] Gholap Dipak Dattatraya.: "Robotic Agriculture Machine", ISSN (Online) : 2319-8753, Volume 3, Special Issue 4, April 2014.

\section{Cite this article as :}

Aye Aye Tun, Zaw Ngwe, "Speed Control of Peanut Planting System", International Journal of Scientific Research in Science and Technology (IJSRST), Online ISSN : 2395-602X, Print ISSN : 2395-6011, Volume 7 Issue 3, pp. 391-396, May-June 2020. Available at doi : https://doi.org/10.32628/IJSRST207386

Journal URL : http://ijsrst.com/IJSRST207386 